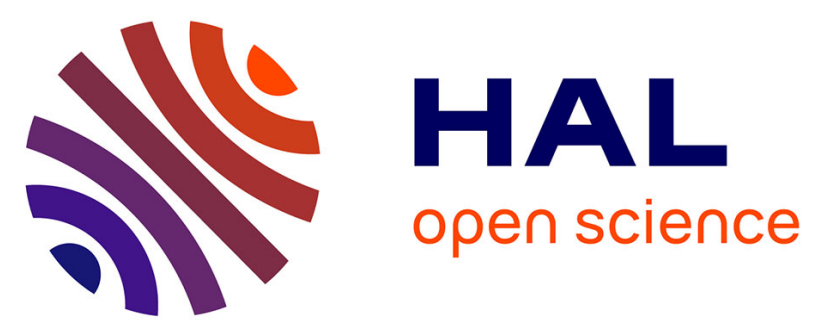

\title{
Ambulatory transradial percutaneous coronary intervention: A safe, effective, and cost-saving strategy.
} Philippe Le Corvoisier, Barnabas Gellen, Pierre-François Lesault, Remy

Cohen, Stéphane Champagne, Anne-Marie Duval, Gilles Montalescot, Simon Elhadad, Olivier Montagne, Isabelle Durand-Zaleski, et al.

\section{To cite this version:}

Philippe Le Corvoisier, Barnabas Gellen, Pierre-François Lesault, Remy Cohen, Stéphane Champagne, et al.. Ambulatory transradial percutaneous coronary intervention: A safe, effective, and cost-saving strategy.: Ambulatory PCI: a safe and effective strategy. Catheterization and Cardiovascular Interventions, 2013, 81 (1), pp.15-23. 10.1002/ccd.24545 . inserm-00784216

\section{HAL Id: inserm-00784216 https://www.hal.inserm.fr/inserm-00784216}

Submitted on 30 Oct 2013

HAL is a multi-disciplinary open access archive for the deposit and dissemination of scientific research documents, whether they are published or not. The documents may come from teaching and research institutions in France or abroad, or from public or private research centers.
L'archive ouverte pluridisciplinaire HAL, est destinée au dépôt et à la diffusion de documents scientifiques de niveau recherche, publiés ou non, émanant des établissements d'enseignement et de recherche français ou étrangers, des laboratoires publics ou privés. 


\section{Ambulatory transradial percutaneous coronary intervention: a safe, effective and cost-saving strategy}

Philippe Le Corvoisier ${ }^{1,2,3}$, MD, PhD; Barnabas Gellen ${ }^{4}, \mathrm{MD}, \mathrm{PhD}$; Pierre-François

Lesault $^{4}, \mathrm{MD}$; Remy Cohen ${ }^{5}$, MD; Stéphane Champagne ${ }^{4}$, MD; Anne-Marie Duval ${ }^{6}, \mathrm{MD}$ Gilles Montalescot ${ }^{7}, \mathrm{MD}, \mathrm{PhD}$; Simon Elhadad ${ }^{5}, \mathrm{MD}$; Olivier Montagne ${ }^{1,2,3}$, MD; Isabelle Durand-Zaleski ${ }^{8}$, MD, PhD; Jean-Luc Dubois-Randée ${ }^{2,6}, \mathrm{MD}, \mathrm{PhD}$; Emmanuel Teiger ${ }^{2,4}$, $\mathrm{MD}, \mathrm{PhD}$

\section{Author affiliations}

${ }^{1}$ Inserm, Centre d'Investigation Clinique 006, U955 équipe 3, Créteil, 94000, France

${ }^{2}$ Université Paris Est, Faculté de Médecine, Créteil, 94000, France

${ }^{3}$ AP-HP, Groupe Hospitalier Henri Mondor, Pole Recherche Clinique et Santé Publique, Centre d'Investigation Clinique 006, Créteil, 94000, France

${ }^{4}$ AP-HP, Groupe Hospitalier Henri Mondor, Département de Cardiologie Interventionnelle, Créteil, 94000, France

${ }^{5}$ Hôpital de Lagny-Marne la Vallée, Service de Cardiologie, Lagny sur Marne, 77405, France

${ }^{6}$ AP-HP, Groupe Hospitalier Henri Mondor, Fédération de Cardiologie, Créteil, 94010, France

${ }^{7}$ AP-HP, Groupe Hospitalier Pitié-Salpétrière, Service de Cardiologie, Paris, 75013, France

${ }^{8}$ AP-HP, Groupe Hospitalier Henri Mondor, Service de Santé Publique, Créteil, 94010 , France

Study performed at: Henri Mondor University Hospital, Créteil, France; Lagny-Marne la Vallée General Hospital, Lagny, France; and Pitié-Salpêtrière University Hospital, Paris, France.

\section{Address for correspondence:}

Philippe Le Corvoisier, Hôpital Henri Mondor, Centre d'Investigation Clinique 006, 51 Avenue du Maréchal de Lattre de Tassigny, Créteil, 94010, France Phone: +33149813796 Fax: +33149813797

E-mail: philippe.lecorvoisier@hmn.aphp.fr

Short running title: Ambulatory PCI: a safe and effective strategy

Key words: percutaneous coronary intervention; radial approach; ambulatory procedure; safety; economic evaluation 
Abstract

Objectives: The aim of this prospective, multicenter study was to assess the safety, feasibility, acceptance, and cost of ambulatory transradial percutaneous coronary intervention (PCI) under the conditions of everyday practice. Background: Major advances in PCI techniques have considerably reduced the incidence of post-procedure complications. However, overnight admission still constitutes the standard of care in most interventional cardiology centers. Methods: Eligibility for ambulatory management was assessed in 370 patients with stable angina referred to three high-volume angioplasty centers. Based on prespecified clinical and PCI-linked criteria, 220 patients were selected for ambulatory PCI. Results: The study population included a substantial proportion of patients with complex procedures: $115(52.3 \%)$ patients with multivessel coronary artery disease, $50(22.7 \%)$ patients with multilesion procedures, and 60 (21.5\%) bifurcation lesions. After a 4 to 6 hours observation period, 213 of the 220 patients $(96.8 \%)$ were cleared for discharge. The remaining 7 (3.2\%) patients were kept overnight for unstable angina $(\mathrm{n}=1)$, atypical chest discomfort $(n=2)$, puncture site hematoma $(n=1)$, or non-cardiovascular reasons $(n=3)$. Within 24 hours after discharge, no patients experienced readmission, stent occlusion, recurrent ischemia, or local complications. Furthermore, $99 \%$ of patients were satisfied with ambulatory management and $85 \%$ reported no anxiety. The average non-procedural cost was lower for ambulatory PCI than conventional PCI (1,230 \pm 98 Euros vs. 2,304 \pm 1814 Euros, $\left.\mathrm{p}<10^{-6}\right)$. Conclusions: Ambulatory PCI in patients with stable coronary artery disease is safe, effective, and well accepted by the patients. It may both significantly reduce costs and optimize hospital resource utilization. 


\section{Abbreviation list:}

CPK: creatine phosphokinase

DRG: diagnosis-related group

ECG: electrocardiogram

MACCE: major adverse cardiac or cerebrovascular events

PCI: percutaneous coronary intervention 


\section{INTRODUCTION}

The number of percutaneous coronary interventions (PCIs) has increased steadily in recent years $(1,2)$. In many interventional cardiology centers, admissions for PCI represent a significant burden on available resources. Shortening the hospital stay required for PCI would be expected to decrease costs and to optimize healthcare resource utilization.

Diagnostic coronary angiography is routinely performed on an outpatient basis with no increase in complication rates compared to inpatient coronary angiography (3). By contrast, most interventional centers keep patients overnight for observation after PCI (4). This practice reflects concern about the risk of subacute stent thrombosis and vascular complications. However, overnight observation may not be necessary in all patients. Dual antiplatelet therapy has markedly decreased the incidence of stent thrombosis $(5,6)$. Furthermore, subacute stent thrombosis usually occurs several days after the procedure and, therefore, patient outcomes are not modified by 24 hours of observation instead of same-day discharge (7).

The safety of same-day discharge after PCI needs to be clearly established before this method can be applied in daily practice. To date, few large-scale prospective studies have evaluated the feasibility and safety of this new patient management strategy (8-12). In most of these previous studies, patients were discharged on the day of PCI, but many of them were hospitalized at least the day before the procedure for pre-procedure assessment or transferred from another hospital. Our study was one of the first in which patients were admitted and discharged on the day of PCI. The aim of this multicenter prospective study was to assess the safety, cost, and acceptability of transradial PCI performed on an ambulatory basis. 


\section{MATERIALS AND METHODS}

\section{Study design}

The study protocol conformed to the ethical guidelines of the Declaration of Helsinki and was approved by the institutional review board of our institution. A written informed consent was obtained from each patient.

This prospective, multicenter, interventional study was conducted from June 2007 to February 2009 in three high-volume angioplasty centers in France. Eligibility for ambulatory management was assessed in 370 consecutive patients with stable angina and/or silent myocardial ischemia who underwent coronary angiography and ad hoc PCI after admission in a day hospitalization unit. The patients were evaluated for same-day discharge at the end of the procedure, based on pre-specified clinical, social, and PCI-related criteria (Figure 1). Two hundred-twenty patients were selected for ambulatory management and kept under observation for 4- to 6-hours in a day hospitalization unit (Figure 2).

\section{Pharmacological treatment}

All patients were pre-treated with aspirin ( $\geq 75 \mathrm{mg} /$ day) for more than 3 days. A 600 mg clopidogrel loading dose was administered to patients, including those already on maintenance clopidogrel treatment $(75 \mathrm{mg} /$ day). During the procedure, anticoagulation was achieved with a single subcutaneous injection of enoxaparin at admission or with a bolus of unfractionated heparin (70 IU/kg) injected immediately after insertion of the arterial sheath. After PCI, patients were maintained on aspirin indefinitely and on clopidogrel according to current guidelines for bare metal stents and drug-eluting stents (13). Other cardiac medications were continued as clinically indicated. 


\section{PCI procedure}

The sheath was inserted in the radial artery under local anesthesia using the standard Seldinger technique. A vasodilating mixture of verapamil $(2.5 \mathrm{mg})$ and isosorbide dinitrate (1 mg) was administered intra-arterially to prevent radial artery spasm. Coronary stenting was performed using standard techniques and according to international guidelines (13). The choice of the PCI strategy was at the operator's discretion. The arterial sheath was removed immediately after the end of the intervention. Hemostasis was achieved using the TR Band ${ }^{\mathrm{TM}}$ radial compression device (Terumo, Somerset, NJ, USA).

\section{Triage and discharge}

At the end of the procedure, patients were transferred to the day hospitalization unit and were allowed to walk freely after 2 hours of bed rest. Then, 4 to 6 hours after PCI, an electrocardiogram and clinical examination were systematically performed by a cardiologist (11). Patients were cleared for discharge if they had no puncture site complications, chest pain, or electrocardiographic changes during the observation period. Patients were instructed to contact their cardiologist or the coronary intensive care unit of the hospital where PCI was performed in the event of complications during the following night.

\section{Follow-up}

On the day after PCI, a phone interview was conducted by a cardiologist to record all post-procedural complications including re-admissions, chest pain, and puncture site complications. Patient satisfaction and degree of anxiety were evaluated using standardized questionnaires (see below). Patients were asked if they visited their general practitioner or cardiologist for any of the above-mentioned reasons. Serum troponin I and creatine phosphokinase (CPK) levels were measured 18 to 24 hours after PCI in outpatient 
laboratories and the results were faxed to the investigators. A second phone interview was conducted by a physician 1 month after PCI to assess the incidence of emergency readmission, angina, dyspnea, and puncture site complications.

\section{Patient comfort and satisfaction}

Patient comfort and satisfaction were evaluated during the phone interview on the day after PCI using a simple questionnaire that offered three response options for satisfaction ("very satisfied", "satisfied", and "not satisfied") (14), three for anxiety ("not anxious", "anxious", and "very anxious"), and two for willingness to accept outpatient PCI in the future ("yes" and "no") $(14,15)$.

\section{Economic evaluation}

French hospitals are financed by a diagnosis-related group (DRG)-based prospective payment system. However, the primary focus of this economic evaluation was to help a decision process at the hospital, not the payer, level. We adopted therefore the perspective of the hospital, assuming that for the present the DRG tariff would remain identical, regardless of the length of stay reduction.

Patient undergoing ambulatory PCI were compared to a group of patients with stable angina, without comorbidities, and undergoing conventional PCI in non-study centers in 2009.

We estimated the cost of ambulatory PCI using microcosting techniques. The total cost of the procedure was divided into non-procedural and procedural costs (cost of supplies, devices, drugs and cardiac catheterization laboratory utilization). The units of physical inputs required for the economic evaluation were collected prospectively at the patient level. 
The cost of conventional inpatient PCI was similarly estimated by microcosting. We used the microcosting performed yearly to update DRG tariffs in 1,820 patients with stable angina treated in comparable university hospitals in the Paris region (16). Unit costs are presented in Table $1(16,17)$. All costs were inflated to reflect 2012 euros. We tested the robustness of our results in a univariate sensitivity analysis of the duration of conventional PCI admission.

\section{Study objectives}

The primary objective of this study was to evaluate the safety of ambulatory PCI as assessed by: the rate of re-admission for any reason within the first 24 hours after ambulatory PCI, the rate of hemorrhagic or thrombotic complications at the radial puncture site, the rate of acute stent thrombosis, patient anxiety and patient satisfaction after the procedure. The cost of ambulatory PCI was also evaluated. Successful ambulatory PCI was defined as absence of cardiac or vascular complications within 24 hours after discharge.

\section{Statistical analyses}

Continuous variables were described as mean $\pm \mathrm{SD}$ and compared with a Student $\mathrm{t}$ test. Qualitative variables were compared using a Chi-squared test. Results were considered to be significantly different for $\mathrm{p}$ values $<0.05$. 


\section{RESULTS}

\section{Patients}

The main characteristics of the 220 study patients are listed in Table 2. Patients mean age was 64+/-9.6 years and 197 (89.5\%) were males. Sixty seven patients (30\%) had diabetes mellitus and 123 (56\%) hypertension. All patients had stable angina and/or silent myocardial ischemia evidenced by treadmill testing, scintigraphy, or stress echocardiography.

\section{PCI procedure}

The main angiographic and procedural characteristics are reported in Table 2 . The study population included a substantial proportion of patients with angiographically complex lesions and complex PCI procedures: multivessel coronary artery disease $(n=115 ; 52.3 \%)$, multivessel interventions $(n=31 ; 14.1 \%)$, multilesion procedures $(n=50 ; 22.7 \%)$, restenosis (32 of 279 lesions, 11.5\%), bifurcation lesions (60 of 279, 21.5\%) and chronic total occlusions (24 of $279,8.6 \%$ ).

An unfractionated heparin bolus (70 IU/kg) was administered in $177(80 \%)$ patients for intraprocedural anticoagulation. The remaining 43 (20\%) patients received a single subcutaneous enoxaparin injection at admission. Coronary stents were placed in $218(99.1 \%)$ patients (312 stents for 279 lesions; range: 0-3 stents per patient). Among implanted stents, $70 \%(\mathrm{n}=217)$ were drug-eluting stents. PCI was technically successful in all patients.

\section{Observation and discharge}

Of the 220 patients, $213(96.8 \%)$ were discharged on the day of PCI and returned home. During the 4- to 6-hour observation period, 4 (1.8\%) patients developed medical events requiring overnight admission: one had a clinically significant puncture site 
hematoma with no need for blood transfusion, two had chest pain without ECG modifications, and one had angina with transient ECG modifications (Table 3). In this last patient, myocardial ischemia occurred despite an uncomplicated PCI and was associated with a moderate increase in serum troponin I level (to twice the upper limit of normal). None of these 4 patients required follow-up coronary angiography during the hospital stay.

The remaining $3(1.4 \%)$ patients were kept overnight for non-cardiovascular reasons. Among them, 1 had transport problems and 2 were concerned about complications in the event of same-day discharge.

\section{Follow-up and adverse clinical events}

Table 4 shows the adverse clinical events recorded on day 1 and day 30 . No readmissions and no major adverse cardiac or cerebrovascular events (MACCE) occurred within the first 24 hours. A small increase in plasma troponin-I was observed in $33.5 \%$ of patients on day 1, but troponin-I level was more than three times the upper limit of normal in only $20.9 \%$ of patients.

The 1-month follow-up showed that a secondary end point occurred in one patient. This event was a non-fatal myocardial infarction 4 days after PCI, caused by stent thrombosis and managed by emergency PCI. Interestingly, bedside aggregometry (VerifyNow ${ }^{\circledR}$, Accumetrics, San Diego, CA, USA) showed biological resistance to both aspirin and clopidogrel in this patient. Readmission was required in 3 other patients, on days 3, 7, and 9, respectively, for atypical non-sustained chest discomfort without ECG changes or troponin elevation that did not require emergency coronary angiography. All 3 patients were discharged within 24 to 48 hours after re-admission. We found no relationship between the complication rate and either the angiographic characteristics or the postprocedural increase in plasma troponin I. 


\section{Patient comfort and satisfaction}

Of the 213 patients discharged on the same day as PCI, 212 completed the comfort and satisfaction questionnaire. Among them, 185 (87\%) were very satisfied, 26 (12\%) were satisfied, and only 1 patient was not satisfied with ambulatory management. Furthermore, $180(85 \%)$ patients reported no anxiety during the first 24 hours after discharge, $28(13 \%)$ reported being anxious, and $5(2 \%)$ reported being very anxious. Of the 212 patients, 203 (96\%) were willing to accept ambulatory PCI should they require another PCI procedure. A trend towards less anxiety was observed in patients with a previous history of PCI (12.5\% of patients with a previous history of PCI were anxious or very anxious vs $18.9 \%$ of patients without history of PCI, ns).

\section{Cost analysis}

The average non-procedural cost for all 220 patients included in our study, including the overnight stay for 7 patients, was $€ 1,230 \pm 98$. In the control group of 1,820 patients who underwent conventional PCI in non-study centres during the same period, the median length of stay was 2 days and the average non-procedural cost per patient was higher at $€ 2,304 \pm 1,814$ ( $\mathrm{p}<10^{-6}$ vs ambulatory PCI) (Table 5).

When procedural costs were included $(€ 1,890 \pm 886$ vs $€ 2,026 \pm 1,086$ for ambulatory PCI and conventional PCI, respectively, $\mathrm{p}<0.04)$, the average total cost remained lower for ambulatory PCI $\left(€ 3,120 \pm 888\right.$ vs $\left.€ 4,330 \pm 1317, \mathrm{p}<10^{-6}\right)$. The difference in procedural costs between ambulatory PCI and conventional PCI was due to a lower average number of stents (1.4 in ambulatory PCI patients vs 1.6 for conventional PCI patients). 
Our sensitivity analysis showed that the most important cost driver for conventional PCI was the length of stay. In daily practice, patients are commonly admitted the day before the procedure and discharged one or sometimes two days later. If the total length of stay were two days or less for all patients in the control group, and assuming that no complication would occur, the non procedural costs for conventional PCI would be reduced to $€ 1,535$ and total costs to $€ 3,561$. The cost difference with ambulatory PCI would then be 'only' $€ 441$ but the budget impact would remain important, given the almost 100,000 patients potentially eligible for ambulatory PCI yearly in France. 


\section{DISCUSSION}

Our results indicate that ambulatory PCI using the radial approach is safe, even in patients with complex coronary artery lesions given a high clopidogrel loading dose. Moreover, the one-day strategy significantly decreased the cost of PCI, suggesting a potential for optimizing healthcare resource utilization.

\section{Safety and feasibility of outpatient transradial PCI}

In recent years, major advances in interventional techniques have radically transformed the management of patients undergoing PCI. Dual antiplatelet therapy has reduced the incidence of cardiac ischemic events and stent thrombosis after coronary stenting $(5,6,18)$. The transradial approach has emerged as an alternative to the transfemoral approach, as it is associated with fewer access-site complications and allows early ambulation (19,20). These changes have called into question the need for an overnight hospital stay after PCI in patients with stable angina. Although several large-scale prospective studies have assessed the feasibility and safety of same-day home discharge after PCI $(8-10,12)$, additional data collected under the conditions of everyday practice are required before ambulatory PCI can be used on a routine basis.

Our study showed that ambulatory transradial PCI was feasible and safe even in patients given aggressive antiplatelet therapy before the procedure. These results are in agreement with previous studies of PCI using the transradial $(9,12)$ or transfemoral approach $(8,10,12)$. In our population of clinically stable patients referred for PCI, most of the patients were eligible for ambulatory management. Our simple patient-selection strategy based on pre-defined clinical and angiographic criteria was associated with an excellent safety profile after uncomplicated PCI. However, a few complications occurred within 4-6 hours after PCI in a limited number of patients, indicating that a short post-procedural observation period 
remains mandatory. No specific risk factors for complications were identified in our population. Whereas several previous studies enrolled patients selected on relatively conservative criteria $(8,21-23)$, our population included a high percentage of patients with multivessel interventions, bifurcation lesions, and total coronary occlusions and was therefore representative of patients referred to catheterization laboratories in everyday practice. The risk of ischemic events was not increased in the patients who had complex lesions. Thus, our results show that angiographically severe coronary lesions and a technically complex procedure are not limiting factors for same-day discharge after successful PCI. Furthermore, the moderate increase in plasma troponin level observed in our population was similar to that found in previously published studies (24) and was not associated with short-term post-procedural complications.

\section{Logistical constraints}

In most of the previous studies, many patients were hospitalized before the procedure or transferred from another hospital (9). Similarly, diagnostic coronary angiography was performed before patient inclusion in the study by Heyde et al (10). Our study represents a new step in the management of patients with coronary artery disease. It is one of the first to assess the safety of ambulatory PCI (with same-day admission and discharge of the patients) under the conditions of everyday practice (25). Thus, the patients were referred directly by their cardiologist to the cardiology departments on the morning of the procedure and were discharged on the same day. However, ambulatory PCI is associated with a number of logistical constraints. Close collaboration between the referring cardiologists, general practitioners, and interventional centers is required. Before the procedure, patients must be carefully screened for factors that preclude ambulatory PCI. Moreover, the referring cardiologists must provide antiplatelet therapy management, patient education, and post- 
procedure follow-up $(4,26,27)$. In our experience, the feedback from physicians regarding ambulatory PCI was extremely positive. Greater use of ambulatory PCI has allowed in our centers to cope with the increasing number of PCI procedures.

\section{Acceptance}

Ambulatory PCI can be deemed feasible in everyday practice only if it is well-accepted by the patients. Our results show that ambulatory PCI was extremely well accepted (15). It induced anxiety in only a small percentage of patients and a slight non-significant trend towards less anxiety was observed in patients with a previous history of PCI.

\section{Impact on costs and hospital resources}

Our economic analysis showed that ambulatory PCI was associated with cost savings related to the shortening of the hospital stay. Since early discharge did not result in early readmissions, the reduction of non-procedural cost was not offset by subsequent expenditures.

Only few studies have evaluated the economic consequences of these new patient management strategies after PCI. Even if our study was performed in a different population, our findings are consistent with the cost-analysis of the EASY trial (28). This latter trial showed that same day home discharge after transradial PCI and a bolus of abciximab reduced by $50 \%$ the post-procedural medical costs compared to overnight admission associated with standard abciximab therapy. Other studies in the Netherlands, Canada and USA have reported savings ranging from $€ 258$ to approximately $€ 1,500(\$ 1.961)(10,14,15)$. This heterogeneity could be due to differences in the standard of care (transradial or transfemoral approach), study design and healthcare prices, in addition to the inclusion of procedural costs. 
Ambulatory PCI requires a specific organization of the departments of cardiology to ensure patient follow-up and evaluation before discharge. The development of ambulatory PCI in daily practice will depend on the level of hospital reimbursement assigned by national health authorities or private insurers and the incentives thus generated. The move from conventional to ambulatory PCI should remain financially attractive for hospitals to promote this strategy.

Moreover, ambulatory PCI may optimize healthcare resource utilization and bed availability. The impact of ambulatory PCI on hospital resource management depends on the characteristics of the cardiology intervention center. In high-volume centers, the shorter hospital stay increases patient turn-over and the number of procedures. In other centers, the increase in hospital bed availability might allow the development of other interventional cardiology activities.

\section{Study limitations}

Our study has a number of limitations. It was designed to prospectively evaluate clinical outcomes in a cohort of stable patients selected for ambulatory PCI based on predefined clinical and angiographic criteria. Therefore, our study was an observational assessment of clinical practice and was not powered to identify factors that predicted outcomes. Moreover, the cost analysis was based on reimbursement modalities in France and its results may not apply directly to countries that have different healthcare systems.

\section{CONCLUSIONS}

Ambulatory PCI in patients with stable coronary artery disease is safe, feasible, and well accepted by the patients. The development of this strategy holds promise for decreasing costs and optimizing healthcare resource utilization by shortening hospital stay. 


\section{Acknowledgments}

The authors thank Ms. Dalila Bitari for technical support. The study was funded by the Assistance Publique-Hôpitaux de Paris [Grant number SCR06003 - P060227].

Conflict of interest: Nothing to report. 


\section{REFERENCES}

1. Cook S, Walker A, Hugli O, Togni M, Meier B. Percutaneous coronary interventions in Europe: prevalence, numerical estimates, and projections based on data up to 2004. Clin Res Cardiol 2007;96:375-82.

2. Togni M, Balmer F, Pfiffner D, Maier W, Zeiher AM, Meier B. Percutaneous coronary interventions in Europe 1992-2001. Eur Heart J 2004;25:1208-13.

3. Block PC, Ockene I, Goldberg RJ, Butterly J, Block EH, Degon C, Beiser A, Colton T. A prospective randomized trial of outpatient versus inpatient cardiac catheterization. N Engl J Med 1988;319:1251-5.

4. Bertrand OF, Larose E, De Larochelliere R, Proulx G, Nguyen CM, Dery JP, Gleeton O, Barbeau G, Noel B, Rouleau J, Boudreault JR, Roy L, Rodes-Cabau J. Outpatient percutaneous coronary intervention: Ready for prime time? Can J Cardiol 2007;23 Suppl B:58B-66B.

5. Moussa I, Oetgen M, Roubin G, Colombo A, Wang X, Iyer S, Maida R, Collins M, Kreps E, Moses JW. Effectiveness of clopidogrel and aspirin versus ticlopidine and aspirin in preventing stent thrombosis after coronary stent implantation. Circulation 1999;99:2364-6.

6. Schomig A, Neumann FJ, Kastrati A, Schuhlen H, Blasini R, Hadamitzky M, Walter H, Zitzmann-Roth EM, Richardt G, Alt E, Schmitt C, Ulm K. A randomized comparison of antiplatelet and anticoagulant therapy after the placement of coronaryartery stents. N Engl J Med 1996;334:1084-9.

7. Daemen J, Wenaweser P, Tsuchida K, Abrecht L, Vaina S, Morger C, Kukreja N, Juni P, Sianos G, Hellige G, van Domburg RT, Hess OM, Boersma E, Meier B, Windecker S, Serruys PW. Early and late coronary stent thrombosis of sirolimus- 
eluting and paclitaxel-eluting stents in routine clinical practice: data from a large two-institutional cohort study. Lancet 2007;369:667-78.

8. Banning AP, Ormerod OJ, Channon K, McKenna CJ, Orr W, Boulton B, Bashir Y, Forfar JC. Same day discharge following elective percutaneous coronary intervention in patients with stable angina. Heart 2003;89:665.

9. Bertrand OF, De Larochelliere R, Rodes-Cabau J, Proulx G, Gleeton O, Nguyen CM, Dery JP, Barbeau G, Noel B, Larose E, Poirier P, Roy L. A randomized study comparing same-day home discharge and abciximab bolus only to overnight hospitalization and abciximab bolus and infusion after transradial coronary stent implantation. Circulation 2006;114:2636-43.

10. Heyde GS, Koch KT, de Winter RJ, Dijkgraaf MG, Klees MI, Dijksman LM, Piek JJ, Tijssen JG. Randomized trial comparing same-day discharge with overnight hospital stay after percutaneous coronary intervention: results of the Elective PCI in Outpatient Study (EPOS). Circulation 2007;115:2299-306.

11. Koch KT, Piek JJ, Prins MH, de Winter RJ, Mulder K, Lie KI, Tijssen JG. Triage of patients for short term observation after elective coronary angioplasty. Heart 2000;83:557-63.

12. Slagboom T, Kiemeneij F, Laarman GJ, van der Wieken R. Outpatient coronary angioplasty: feasible and safe. Catheter Cardiovasc Interv 2005;64:421-7.

13. Silber S, Albertsson P, Aviles FF, Camici PG, Colombo A, Hamm C, Jorgensen E, Marco J, Nordrehaug JE, Ruzyllo W, Urban P, Stone GW, Wijns W. Guidelines for percutaneous coronary interventions. The Task Force for Percutaneous Coronary Interventions of the European Society of Cardiology. Eur Heart J 2005;26:804-47. 
14. Khatri S, Webb JG, Carere RG, Amis A, Woolcott J, Chugh S, Humphries KH. Safety and cost benefit of same-day discharge after percutaneous coronary intervention. Am J Cardiol 2002;90:425-7.

15. Glaser R, Gertz Z, Matthai WH, Wilensky RL, Weiner M, Kolansky D, Hirshfeld J, Jr., Herrmann H. Patient satisfaction is comparable to early discharge versus overnight observation after elective percutaneous coronary intervention. J Invasive Cardiol 2009;21:464-7.

16. ATIH. Available at: http://www.atih.sante.fr. Accessed on April 24, 2012.

17. Midy F HM, Métral P. Available at, http://www.ameli.fr/fileadmin/user_upload/documents/POS101_Stents_coronariens_ et_risque_de_re-intervention.pdf. Accessed on April 24, 2012.

18. Movahed MR, Hashemzadeh M, Jamal MM, Ramaraj R. Decreasing in-hospital mortality of patients undergoing percutaneous coronary intervention with persistent higher mortality rates in women and minorities in the United States. J Invasive Cardiol 2010;22:58-60.

19. Brueck M, Bandorski D, Kramer W, Wieczorek M, Holtgen R, Tillmanns H. A randomized comparison of transradial versus transfemoral approach for coronary angiography and angioplasty. JACC Cardiovasc Interv 2009;2:1047-54.

20. Rao SV, Ou FS, Wang TY, Roe MT, Brindis R, Rumsfeld JS, Peterson ED. Trends in the prevalence and outcomes of radial and femoral approaches to percutaneous coronary intervention: a report from the National Cardiovascular Data Registry. JACC Cardiovasc Interv 2008;1:379-86.

21. Chambers CE, Dehmer GJ, Cox DA, Harrington RA, Babb JD, Popma JJ, Turco MA, Weiner BH, Tommaso CL. Defining the length of stay following percutaneous coronary intervention: an expert consensus document from the Society for 
Cardiovascular Angiography and Interventions. Endorsed by the American College of Cardiology Foundation. Catheter Cardiovasc Interv 2009;73:847-58.

22. Laarman GJ, Kiemeneij F, van der Wieken LR, Tijssen JG, Suwarganda JS, Slagboom T. A pilot study of coronary angioplasty in outpatients. Br Heart J $1994 ; 72: 12-5$.

23. Rao SV, Kaltenbach LA, Weintraub WS, Roe MT, Brindis RG, Rumsfeld JS, Peterson ED. Prevalence and outcomes of same-day discharge after elective percutaneous coronary intervention among older patients. Jama 2011;306:1461-7.

24. Feldman DN, Minutello RM, Bergman G, Moussa I, Wong SC. Relation of troponin I levels following nonemergent percutaneous coronary intervention to short- and long-term outcomes. Am J Cardiol 2009;104:1210-5.

25. Khater M, Zureikat H, Alqasem A, Alnaber N, Alhaddad IA. Contemporary outpatient percutaneous coronary intervention: feasible and safe. Coron Artery Dis 2007;18:565-9.

26. Fox K, Garcia MA, Ardissino D, Buszman P, Camici PG, Crea F, Daly C, De Backer G, Hjemdahl P, Lopez-Sendon J, Marco J, Morais J, Pepper J, Sechtem U, Simoons M, Thygesen K, Priori SG, Blanc JJ, Budaj A, Camm J, Dean V, Deckers J, Dickstein K, Lekakis J, McGregor K, Metra M, Morais J, Osterspey A, Tamargo J, Zamorano JL. Guidelines on the management of stable angina pectoris: executive summary: The Task Force on the Management of Stable Angina Pectoris of the European Society of Cardiology. Eur Heart J 2006;27:1341-81.

27. Henein MY, Owen A. Statins moderate coronary stenoses but not coronary calcification: results from meta-analyses. Int J Cardiol 2011;153:31-5.

28. Rinfret S, Kennedy WA, Lachaine J, Lemay A, Rodes-Cabau J, Cohen DJ, Costerousse O, Bertrand OF. Economic impact of same-day home discharge after 
uncomplicated transradial percutaneous coronary intervention and bolus-only abciximab regimen. JACC Cardiovasc Interv 2010;3:1011-9. 


\section{FIGURE LEGENDS}

Figure 1: Inclusion and exclusion criteria.

\section{Figure 2: Patient flow chart.}

Among 370 patients admitted in a day hospitalization unit who underwent coronary angiography and percutaneous coronary intervention (PCI), 220 were found eligible for same-day discharge based on pre-specified clinical, social, and PCI-linked criteria. During the 4- to 6-hour post-PCI observation period, 4 patients developed a cardiovascular event requiring overnight admission. Furthermore, 3 other patients stayed overnight for reasons unrelated to their cardiovascular condition. Thus, 213 patients were discharged on the day of PCI. 
Table 1: Unit costs of hospital resources

\begin{tabular}{lc}
\hline Item & Cost/unit \\
\hline Bare metal stent $^{17}$ & $€ 390$ \\
Drug eluting stent $^{17}$ & $€ 1,483$ \\
Procedural cost (excluding stents) $^{16}$ & $€ 518$ \\
Personnel cost (day shift) $^{16}$ & $€ 270$ \\
Overheads and bed charges per day $^{16}$ & $€ 281$ \\
\hline
\end{tabular}


Table 2: Patient characteristics

\section{Demographic characteristics}

Patients, $\mathrm{n}$

Mean age, y (SD)

$64(9.6)$

Range, y

Male, n (\%)

$197(89.5)$

Hypercholesterolemia, n (\%)

$157(71.4)$

Current/Former smokers, n (\%)

$38(17.3) / 97(44.1)$

Diabetes mellitus, n (\%)

$67(30.5)$

Hypertension, n (\%)

$123(55.9)$

Previous myocardial infarction, n (\%)

Previous percutaneous coronary intervention, $\mathrm{n}(\%)$

$115(52.3)$

Previous coronary artery bypass grafting, $\mathrm{n}(\%)$

Multivessel coronary artery disease, $\mathrm{n}(\%)$

\section{Angiographic characteristics}

Lesions, $\mathrm{n}$

Location of lesion, $\mathrm{n}(\%)$

Left anterior descending artery

$102(36.5)$

Circumflex coronary artery

77 (27.6)

Right coronary artery

$99(35.5)$

Vein graft

$1(0.4)$

Stenosis $(\%)$

$80.1 \pm 12.0$

Restenosis, n (\%)

$32(11.5)$

Bifurcation lesion, $\mathrm{n}(\%)$

$60(21.5)$

Moderate-to-severe calcification, n (\%)

$82(29.3)$

Total coronary occlusion, $\mathrm{n}(\%)$

\section{Percutaneous coronary intervention characteristics}

Procedural success, n (\%)

$220(100.0)$

Balloon angioplasty, $\mathrm{n}(\%)$

Number of stents per procedure (Mean \pm SD)

$1.42 \pm 0.67$

Stent length, mm (Mean \pm SD)

$17.7 \pm 6.3$

Stent diameter, $\mathrm{mm}(\mathrm{Mean} \pm \mathrm{SD})$

$2.97 \pm 0.48$

Multilesion intervention, $\mathrm{n}(\%)$

$50(22.7)$

Multivessel intervention, $\mathrm{n}(\%)$

$31(14.1)$

$6 \mathrm{~F} / 5 \mathrm{~F}$ guiding catheters, $\mathrm{n}(\%)$

$128(58.2) / 92(41.8)$ 
Table 3: Management of the 220 included patients after the 4- to 6-hour observation period

\begin{tabular}{lc}
\hline Same day discharge, $\mathbf{n}(\%)$ & $\mathbf{2 1 3}(\mathbf{9 6 . 8})$ \\
Delayed discharge for cardiovascular reasons, $\mathbf{n}(\%)$ & $\mathbf{4}(\mathbf{1 . 8})$ \\
Myocardial ischemia, n (\%) & $1(0.45)$ \\
Atypical chest pain, n (\%) & $2(0.9)$ \\
Radial hematoma, n (\%) & $1(0.45)$ \\
Emergent repeat PCI, n (\%) & $0(0)$ \\
Delayed discharge for non-cardiovascular reasons, $\mathbf{n}(\%)$ & $\mathbf{3}(\mathbf{1 . 4})$ \\
Transport problems, n (\%) & $1(0.5)$ \\
Anxiety, n (\%) & $2(0.9)$ \\
\hline
\end{tabular}


Table 4: Follow-up data 24 hours and 1 month after ambulatory percutaneous coronary intervention

\begin{tabular}{|c|c|c|}
\hline & $\begin{array}{c}24 \text { hours } \\
(n=213)\end{array}$ & $\begin{array}{l}1 \text { month } \\
(n=213)\end{array}$ \\
\hline Any MACCE & $0(0)$ & $1(0.5)$ \\
\hline Death, n (\%) & $0(0)$ & $0(0)$ \\
\hline Myocardial infarction, $\mathrm{n}(\%)$ & $0(0)$ & $1(0.5)$ \\
\hline Cardiac surgery, n (\%) & $0(0)$ & $0(0)$ \\
\hline Repeat PCI, n (\%) & $0(0)$ & $0(0)$ \\
\hline Stroke, n $(\%)$ & $0(0)$ & $0(0)$ \\
\hline Readmission, $\mathrm{n}(\%)$ & $0(0)$ & $4(1.9)$ \\
\hline Seek medical care without readmission, n (\%) & $0(0)$ & $7(3.3)$ \\
\hline \multicolumn{3}{|l|}{ Markers of myocardial injury } \\
\hline $\mathrm{CPK}>2$ times the upper limit, $\mathrm{n}(\%)$ & $1(0.5)$ & na \\
\hline Troponin I > upper limit, n (\%) & $69(33.5)$ & na \\
\hline Troponin $\mathrm{I}>3$ times the upper limit, $\mathrm{n}(\%)$ & $43(20.9)$ & na \\
\hline Troponin $\mathrm{I}>1 \mu \mathrm{g} / \mathrm{L}, \mathrm{n}(\%)$ & $11(5.3)$ & na \\
\hline
\end{tabular}

$\overline{\mathrm{CPK}}$, creatine phosphokinase; na, not assessed 
Table 5: non-procedural costs of ambulatory and conventional PCI

\begin{tabular}{lll}
\hline Ambulatory PCI $(\mathrm{N}=220)$ & $€$ & p value* \\
\hline
\end{tabular}

Patients with same-day home discharge $(\mathrm{N}=213)$

$€ 1,214 \pm 96$

Personnel (medical and nursing)

$€ 270$

Tests, drugs, supplies, imaging, transport

$€ 663$

Overheads \& bed charges

$€ 281$

Patients with overnight or prolonged stay $(\mathrm{N}=7)$

$€ 1,634 \pm 85$

Personnel (medical and nursing) $€ 285$

Tests, drugs, supplies, imaging, transport $€ 918$

Overheads \& bed charges

$€ 431$

All patients $(\mathrm{N}=\mathbf{2 2 0})$

$€ 1,230 \pm 98$

$<10^{-6}$

\section{Conventional PCI $(\mathrm{N}=\mathbf{1 , 8 2 0})$}

All patients $(\mathrm{N}=\mathbf{1 , 8 2 0})$

$€ 2,304 \pm 1,814$

Personnel (medical and nursing)

$€ 855$

Tests, drugs, supplies, imaging, transport

$€ 918$

Overheads \& bed charges

$€ 531$

*: comparison between the average non-procedural cost of ambulatory PCI vs conventional PCI.

Note: figures were rounded to the nearest $€$ 


\section{Figure 1}

\section{Inclusion criteria}

- Age > 18 y.o.

- Stable angina

\section{Exclusion criteria}

\section{- Clinical criteria}

- Unstable angina, NSTEMI, STEMI

- Symptomatic heart failure and/or LVEF $<35 \%$

- Severe chronic renal failure (creatinine clearance $<30 \mathrm{ml} / \mathrm{min}$ )

- Oral anticoagulant therapy

- Social criteria

- Concerns about patient compliance

- Residence >60 min away from hospital

- Inadequate home support

- PCI-linked criteria

- Radial approach not feasible

- Use of glycoprotein Ilb/IIla receptor antagonist

- Final TIMI flow $<3$

- Coronary artery dissection

- Occlusion of a significant (>1 mm) side branch

- Persistent chest pain

- Hemodynamic instability during the procedure

- Ventricular arrhythmias during the procedure

- Procedure completed after 2 p.m. 
Figure 2

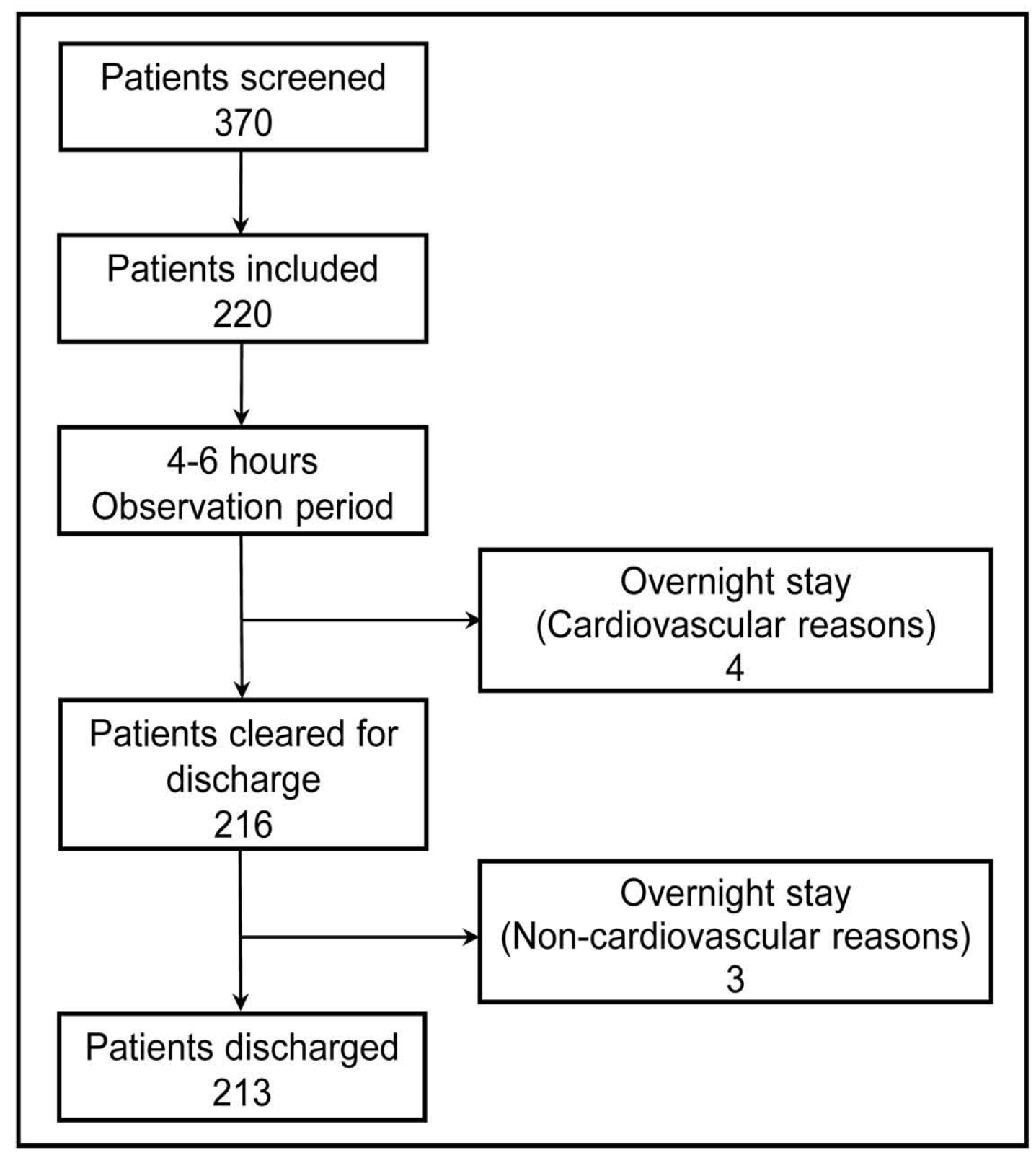

